\title{
O processo de escolha de Gestores Escolares no Estado do Amapá
}

\author{
Norma Cordeiro da Silva \\ Universidade Estadual do Ceará - UECE \\ Alexandre Almeida Barbalho \\ Universidade Estadual do Ceará - UECE
}

\section{Resumo}

Este artigo é oriundo da Dissertação de Mestrado intitulada: A Política Pública Educacional no Estado do Amapá: 0 processo de escolha de Gestores Escolares e a Gestão Democrática das Escolas Públicas Estaduais no quinquênio (2014-2018). Tem como escopo principal investigar a implementação da política pública de escolha de dirigentes escolares pelo processo de gestão democrática nas unidades escolares estaduais do Estado do Amapá, sem a pretensão de apresentar avaliações e resultados definitivos no recorte temporal estabelecido. Neste estudo estão contidos os objetivos específicos: a) pesquisar as relações entre a Política Pública Educacional a legislação da Gestão Democrática no Estado do Amapá; b) investigar como ocorrem a democracia, a participação, a representação e a Gestão Escolar Democrática no Estado do Amapá; e, c) Diagnosticar as ideias, objetivos, resultados e perspectivas da Gestão Democrática no olhar dos envolvidos com esse processo neste ente federado. Os resultados apontaram para um cenário em construção nesta temática.

Palavra-chave política pública educacional; gestão democrática; democracia.

\begin{abstract}
This article comes from the Master's Dissertation entitled: Educational Public Policy in the State of Amapá: The process of choosing School Managers and the Democratic Management of State Public Schools in the five-year period (2014-2018). Its main scope is to investigate the implementation of the public policy of choosing school leaders by the democratic management process in the state school units of the state of Amapá, without the intention of presenting definitive evaluations and results in the established time frame. This study contains the specific objectives: a) to research the relations between the Educational Public Policy and the Democratic Management legislation in the State of Amapá; b) investigate how democracy, participation, representation and Democratic School Management occur in the State of Amapá; and c) Diagnose the ideas, objectives, results and perspectives of
\end{abstract}


Democratic Management in the eyes of those involved with this process in this federated entity. The results pointed to a scenario under construction in this theme.

Key-word educational public policy; democratic management; democracy.

\section{Introdução}

O modo como os diretores escolares assumiam os seus papéis e poder se configurou historicamente pela indicação política feita pelos chefes do poder executivo. Com o advento da Constituição Federal (CF), conhecida como constituição cidadã, há esforços no intuito de organizar os diversos setores sociais como é o caso da educação.

O cenário de participação nos processos decisórios e como consequência, o processo de redemocratização abriram espaço para o debate de assuntos que tinham ficado de lado como é o caso da gestão das unidades de ensino, que por décadas contaram com gestores indicados, ás vezes, sem possuírem, no mínimo, a formação na área educacional.

Em 1988 é criado o Estado do Amapá que promulga a sua Constituição Estadual em 1991, esta que delega alguns poderes ao chefe do poder executivo estadual, dentre eles, a prerrogativa de indicar todos os cargos do sistema administrativo educacional que compõem o Estado. Por dezenove anos essa prática foi única e hegemônica, até que no ano de 2010, surge a lei 1.503 que dispõe sobre a regulamentação da gestão democrática escolar nas unidades escolares do sistema estadual de ensino.

Tal legislação cria uma ruptura entre o antigo modo de escolha de gestores escolares e aponta uma alternativa de escolha destes dirigentes. Este contexto se configura no escopo do presente artigo, o qual objetiva de modo geral, investigar a implementação da política pública de escolha de dirigentes escolares pelo processo de gestão democrática nas unidades escolares estaduais do Estado do Amapá no período de 2014 a 2018.

Deste objetivo geral originaram-se três objetivos específicos, a saber: pesquisar as relações entre a Política Pública Educacional a legislação da Gestão Democrática no Estado do Amapá; investigar como ocorrem a democracia, a participação, a representação e a Gestão Escolar Democrática no Estado do Amapá e Diagnosticar as ideias, objetivos, resultados e perspectivas da Gestão Democrática no olhar dos envolvidos com esse processo neste ente federado.

A pesquisa das relações entre a Política Pública Educacional e a legislação da Gestão Democrática foi necessária para se compreender como ocorre este fenômeno no Estado do Amapá; ao investigar como ocorrem a democracia, a participação, a representação e a Gestão Escolar Democrática neste local, se pretende ampliar o horizonte de compreensão do viés democrático e de redemocratização trazidos pela Constituição de 1988; ao se diagnosticar as ideias, objetivos, resultados e perspectivas da Gestão Democrática no olhar dos envolvidos com esse processo, objetiva-se analisar o período transcorrido e propor sugestões de mudança que visem a melhoria na implementação da política pública em questão. 


\section{Trilhar metodológico}

A Seleção dos Agentes envolvidos com o processo de gestão democrática no Estado do Amapá ocorreu por seu grau de envolvimento ou importância na referida ação. Feito a seleção, foi realizada a separação destes em dois grupos, a saber, grupo gestor: Secretaria de Estado da Educação no período do primeiro pleito para gestores escolares do Estado do Amapá (2012 a 2014)1; Ex-Presidente do Sindicato dos Servidores Públicos em Educação no Amapá (SINSEPEAP) (2010-2016)2; Atual Presidente do SINSEPEAP (2017-2019)3; Diretor de uma Escola Estadual que passou pelo processo de Gestão Democrática (20142017 e 2017-2019)4; Vice Presidente do Conselho Escolar da mesma unidade de ensino5.

O outro grupo é formado por quatro6 membros da Coordenação Permanente de Organização e Acompanhamento dos Processos Eleitorais (CEPE), vale ressaltar que esta comissão é composta por oito pessoas. Elas estiveram à frente dos processos seletivos de 2014 e 2017 e fazem parte da Secretaria de Estado da Educação do Estado do Amapá (SEED/AP).

Para a coleta de dados, optou-se pela entrevista como principal elemento de reunião das informações no o tratamento dos dados obtidos, transcrição, análise de conteúdo e discussão dos resultados foram utilizados autores já consolidados nesta área do conhecimento. Segundo Bardin (1977, p. 10) "Ao desempenharem o papel de 'técnicas de ruptura' face à intuição aleatória e fácil, os processos de análise de conteúdo obrigam à observação de um intervalo de tempo entre o estímulo-mensagem e a reação interpretativa".

Realizado as entrevistas foi utilizado o método qualitativo que nas Sinopses será expresso por Sínteses interpretativas (frases) dos pontos convergentes e divergentes de cada respondente as perguntas específicas, conforme Minayo (2009). Esta autora afirma que a pesquisa qualitativa responde a questões muito particulares. Ela se ocupa, nas Ciências Sociais, com um nível de realidade que não pode ou não deveria ser quantificado, desse modo, o método quantitativo, não será descartado, mas servirá de suporte.

\section{Resultados e discussão}

Nesta seção será discutido o resultado das entrevistas dos Agentes envolvidos com o processo de gestão democrática no Estado do Amapá, grupo gestor: Secretaria de Estado da Educação no período do primeiro pleito para gestores escolares do Estado do Amapá (2012 a 2014); Ex-Presidente do Sindicato dos Servidores Públicos em Educação no Amapá (SINSEPEAP) (2010-2016); Atual Presidente do SINSEPEAP (2017-2019); Diretor de uma Escola Estadual que passou pelo processo de Gestão Democrática (2014-2017 e 20172019); Vice Presidente do Conselho Escolar da mesma unidade de ensino. E o grupo formado por quatro membros da Coordenação Permanente de Organização e Acompanhamento dos Processos Eleitorais (CEPE).

\footnotetext{
1 Nos Resultados e Discussão, aparecerá como entrevistado 01. A atual secretaria de Estado da Educação foi procurada reiteradas vezes e não foi obtido sucesso no que concerne a entrevista.

2 Entrevistado 02.

3 Entrevistado 03.

4 Entrevistado 04, o referido Gestor está no cargo de 2014 até o término deste trabalho.

5 Entrevistado 05

6 Entrevistados 06, 07, 08 e 09.
} 
O quadro a seguir destina-se a mostrar os principais pontos convergentes e divergentes no olhar destes cinco7 gestores que de algum modo estão atrelados desde o ano de 2014 com a implementação da lei 1.503 de 2010 que estabelece a obrigatoriedade para e eleição de diretores escolares no Estado do Amapá.

Quadro 01 - SINOPSE: Gestores envolvidos com o processo de Gestão Democrática no Estado do Amapá, pontos semelhantes e divergentes

\begin{tabular}{|c|c|}
\hline PONTOS SEMELHANTES & PONTOS DIVERGENTES \\
\hline$>$ A Gestão Democrática Garante relativa autonomia; & \multirow{4}{*}{$\begin{array}{l}\text { A gestão da Secretaria de Educação do } \\
\text { Estado do Amapá declara que deu todo } \\
\text { suporte aos processos de Gestão } \\
\text { Democrática, entretanto, os demais } \\
\text { representantes dizem que faltou apoio e } \\
\text { acompanhamento; }\end{array}$} \\
\hline$>$ Ocorreu a Descentralização Administrativa; & \\
\hline $\begin{array}{l}\text { Implantação e revitalização do conselho escolar via } \\
\text { eleição de diretores; }\end{array}$ & \\
\hline \multirow{2}{*}{$>$ Motivação/acompanhamento/apoio; } & \\
\hline & \multirow{6}{*}{$\begin{array}{l}\text { A Implementação da Lei } 1.503 \text { de } 2010 \text { é } \\
\text { incipiente, pelo tempo que foi executada no } \\
\text { final de um mandato eletivo e no intervalo } \\
\text { que se encontra atualmente desenvolvendo o } \\
\text { pleito, ou seja, } 396 \text { escolas e somente } 10 \\
\text { com a gestão democrática, via eleição de } \\
\text { Gestores. }\end{array}$} \\
\hline$>$ Formação Continuada: Cursos, Fóruns, Seminários; & \\
\hline$>$ A lei 1.503 de 2010 & \\
\hline $\begin{array}{l}\text { Conflito entre os pares Sindicado/SEED- } \\
\text { AP/Escola; }\end{array}$ & \\
\hline$>$ Tipo de modalidade do Cargo; & \\
\hline$>$ Participação Institucional; & \\
\hline
\end{tabular}

Fonte: Elaborado pela autora a partir das respostas as entrevistas

Os principais pontos semelhantes que merecem destaque são a garantia de uma Gestão Democrática com relativa autonomia frente aos processos decisórios que são característicos de unidades escolares, ou seja, a equipe gestora pode dar encaminhamento aos seus problemas internos, ouvido a comunidade escolar. Assim:

Nossa intenção na época era dar autonomia para as escolas, a partir da implantação do Conselho Escolar, passaria a ser uma Gestão Compartilhada, então, o Gestor teria esta possibilidade de ser escolhido, não só ele como a equipe gestora: diretor, adjunto, secretário seriam escolhido pela comunidade escolar [...] (Entrevistado 1).

Poder escolher o gestor escolar, é mais que realizar uma eleição, é colocar de forma efetiva a participação, os atores envolvidos com o processo como salienta Avritzer (2011), é dar voz e vez para quem é parte integrante do processo. "A gestão democrática vem justamente para que toda a comunidade escolar docente e não docente; pais dos alunos e alunos envolvidos possam escolher seus representantes para administrarem as escolas." (Entrevistado 3).

Outro ponto que merece destaque é a Descentralização Administrativa que as escolas de gestão democrática receberam conforme o Título I - da Gestão Democrática Escolar do Ensino Estadual, artigo primeiro, inciso quinto "Art. 1ํ [...] V - garantia de descentralização do processo educacional; [...]." (AMAPÁ, 2010). Alguns pontos desta descentralização são alvos de ressalvas, como a que se segue:

7 Entrevistados: 01, 02, 03, 04 e 05, conforme metodologia apresentada no presente trabalho. 
Olha a descentralização desse processo de gestão escolar, eu não vejo com muito bons olhos, isso, não teve um processo, não teve uma regularização dessa lei 1.503. Por exemplo, a escola militar, nunca vi, escola militar em escola pública, geralmente escolas militares são privadas. (Entrevistado 3)

Perpendicular à autonomia e descentralização, tem-se o fator orçamentário, o qual vincula as unidades de ensino a Secretaria de Estado de Educação como as outras unidades educacionais do sistema estadual de ensino, ou seja, as escolas de gestão democrática não recebem a autonomia financeira.

A promulgação da lei estadual 1.503 de 2010 se tornou um divisor entre a velha maneira de indicar os cargos de dirigentes escolares salvaguardado no texto constitucional do Estado do Amapá pelo direito de escolher de forma democrática esses diretores, vale destaque o fato da lei ser do ano de 2010 e a primeira eleição ocorrer apenas no ano de 2014, ou seja, a demora em implementar este tipo de política pública implica diretamente no viés democrático preconizado pela legislação.

Do mesmo modo, entre os respondentes há pontos divergentes que merecem alguns comentários e o primeiro deles é o fato de ser uníssona a Secretaria de Educação do Estado do Amapá declarar que deu todo suporte necessário ao processo de escolha de diretores escolares, entretanto, os demais representantes dizem que faltou apoio e acompanhamento;

\begin{abstract}
Nós temos uma falha, que está comissão é com membros indicados pelo sindicato e membro indicado pela Secretaria do Estado da Educação, o que aconteceu e acontece que estas pessoas todas tem atividades, então faz-se o processo de eleição e não se acompanha o processo da implementação, porque estas pessoas não estão a disposição para pra isto. (Entrevistado 2)
\end{abstract}

Dessa maneira, o processo de escolha de diretores escolares demonstra ter um ponto divergente a ser corrigido que trata, tanto da SEED-AP, quanto das demais instâncias que acompanham esse processo. A Secretaria de Educação deve ser a responsável por conduzir todo esse processo pelo fato de ser a mantenedora das unidades escolares e a instituição que sistematiza toda a política em nível de Estado.

Assim, essa política pública ainda se mostrar parca nos sistemas de ensino das unidades federadas em suas escolas da educação básica. Diante disso, faltam mais valorização e efetivação dessa prática de política educacional em todo Brasils, e particularmente no Estado do Amapá. A esse respeito, Lück (2011, p. 26), acrescenta que:

[...] é observado que em grande parte essa cultura se desenvolve em reação às interferências muitas vezes erráticas e descontínuas dos sistemas de ensino e algumas vezes até mesmo contraditórias em relação aos princípios propostos [...] De qualquer forma, medidas promovidas pelos sistemas de ensino para a melhoria da gestão escolar, mediante seleção de diretores se apresentam restritas em seus

\footnotetext{
8 Era praticada em 17 Estados brasileiros desde 1998 a proposta de escola, um estilo de gestão acompanhados dos segmentos representação, no caso: o conselho escolar, o segmento do grêmio e com evidência a introdução do processo de eleição de diretores (LÜCK, 2006).
} 
resultados, em decorrência de circunscrições de origem, por apresentarem características limitadoras [...]

Entre 2014 e 2017 mais de 30 Escolas Participaram das Formações oferecidas que compreenderam: orientação e implementação dos conselhos escolares, entretanto, poucas conseguiram organizar seus conselhos escolares. 0 ano de 2017 foi marcado por reuniões, Fóruns, Cursos, entre outros. No primeiro pleito houve a eleição de 4 (quatro) diretores, na segunda contou-se com os já existentes e mais 6 (seis) novos gestores perfazendo um total de 10 (dez).

Assim, faz-se necessário compreender a visão dos membros da Coordenação Permanente de Organização e Acompanhamento dos Processos Eleitorais (CEPE), no que concerne aos pontos convergentes e divergentes da lei 1.503 de 2010, eles são designados para a elaboração e acompanhamentos dos processos seletivos de escolha de gestores escolares.

Quadro 02 - SINOPSE: Coordenação Permanente de Organização e Acompanhamento dos Processos Eleitorais (CEPE), pontos semelhantes e divergentes

\begin{tabular}{|c|c|}
\hline PONTOS SEMELHANTES & PONTOS DIVERGENTES \\
\hline $\begin{array}{l}\text { Lei } 1503 / 2010 \text { orienta a criação do comitê } \\
\text { avaliativo das políticas públicas da educação } \\
\text { estadual com objetivo de acompanhar, monitorar, } \\
\text { avaliar as políticas públicas educacionais do } \\
\text { sistema estadual; }\end{array}$ & $\begin{array}{l}\checkmark \text { Primeiro pleito as escolas foram chamadas } \\
\text { por edital, quem se inscreveu foi por } \\
\text { interesse próprio; }\end{array}$ \\
\hline$>$ Eleição para diretor em 10 escolas; & $\begin{array}{l}\checkmark \text { No segundo pleito as escolas foram } \\
\text { indicadas para serem de gestão democrática; }\end{array}$ \\
\hline$>$ A CEPE trabalha para implantação da lei; & $\begin{array}{l}\text { Reconhecer a prioridade zero de implantar o } \\
\text { comitê, um instrumento que ajudará na } \\
\text { qualidade do ensino e no desenvolvimento } \\
\text { da escola na política de gestão democrática; }\end{array}$ \\
\hline $\begin{array}{l}\text { A Constituição Estadual dá o direito ao executivo } \\
\text { nomear e exonerar os cargos de diretor escolar; }\end{array}$ & $\begin{array}{l}\text { A lei continua na gaveta, ela possui o caráter } \\
\text { democrático e participativo. }\end{array}$ \\
\hline$>$ Divulgação, Formação; Votação. & $\checkmark \quad$ A lei precisa ser alimentada. \\
\hline
\end{tabular}

Fonte: Elaborado pela autora a partir das respostas as entrevistas

Como pontos uníssonos entre os membros do CEPE tem-se que: a Lei 1503/2010 orienta a criação do comitê avaliativo das políticas públicas da educação estadual com objetivo de acompanhar, monitorar, avaliar as políticas públicas educacionais do sistema estadual, neste bojo houve as eleições para diretores em 10 escolas. Essa coordenação trabalha para implantar a lei no Estado. Desse modo, o voto torna-se o mais importante propulsor do viés democrático, logo:

[...] o povo não quis o candidato que se apresentou, então não votou, ficou abaixo do número proposto pra eleger alguém, não pode assumir. (Entrevistado 6)

A escola está trabalhando para meia dúzia, para eu atender aquelas pessoas que votaram em mim e ai eu trabalho para aquelas pessoas, para aquelas que não votaram em mim como se elas não existisse e quando isso acontece, a equipe que trabalha me cobra porque eu estou atendendo aquele que não votou. (entrevistado 9) 
A democracia tem estado ainda em regras de contato com o autoritarismo sob o modelo do sistema representativo. Este tem se materializado pelas esferas privadas que regulam a vida política com limitação funcional (submissão a grupos, a interesses de uns, do governo) no ceder a vontade da maioria, vindo assim, acentuar o distanciamento do sistema representativo de sua base genuína. Dessa forma, passando a servir a interesses particulares, que retratam a supervalorização deste modelo, em detrimento das formas de participação coletiva.

Tem-se observado a esse respeito, que a participação é o determinante para firmar o mecanismo de deliberação de poder, porém, está condicionada a acontecer esporadicamente e ainda agregada aos fatos reais que mutuamente estão, para efeito de um único momento, como as tomadas de decisões no processo eleitoral, que representa o ponto culminante do seu exercício, o voto.

Para tanto, o eleitor precisa aprender a ter percepção, ter vontade de conhecer e refletir, ter vontade de interferir, ter interesse de discutir as informações vinda dos meios de comunicação, principalmente praticar estas competências pelo acesso da escola, um espaço organizacional que requer mudanças no sistema público, no Estado e no modelo de política de Educação (já em defesa do processo de democratização).

0 voto foi conquistado através de um processo histórico secular acirrado, de desigualdade e continua sendo. É fruto desta matriz histórica, uma raiz profunda vinda da afirmação dos direitos naturais, segundo Rousseau (2002), e deste inerente conceito veio à expansão do direito à vida, liberdade de expressão, a participar do Estado ou governo, de votar e ser votado, ou seja, garantiu a liberdade de escolha em todas as áreas da vida, como a educação.

Segundo Ghirardi e Cunha (2012, p.164) neste estágio de organização do Estado moderno, voto e participação política são vistos como indissociáveis, pois são “[...] a garantia de que uma era de arbítrio e opressão está superada e de que não voltará. Eles são um direito fundamental, inalienável e em tudo ligado à identidade política do cidadão. [...] o mecanismo privilegiado para a emancipação social". Dessa forma, o voto e a participação envolvem a sociedade em escolhas que emergem da manifestação da vontade individual (conservadora) e a vontade coletiva (participação política), esta última traz um ponto crucial, sob o efeito alienante quanto à apatia da participação política expressão repicada perante um processo organizativo coletivo.

Realizado as devidas considerações sobre os pontos semelhantes, vejamos sobre o que os membros do CEPE julgam como pontos divergentes: primeiramente tem-se que para o primeiro pleito de gestão escolar democrática do Estado do Amapá as escolas foram chamadas por edital e quem se inscreveu fez por interesse próprio, já no segundo pleito as escolas foram indicadas para serem de gestão democrática;

Por conseguinte, os membros do CEPE relatam a prioridade de se criar e implantar o Comitê de Avaliação das Políticas Públicas Estadual que deve realizar o assessoramento, acompanhamento, monitoração e avaliação para implementação do projeto político da gestão democrática para que ocorra nas unidades escolares o processo decisório tanto dos conselhos como da escolha de diretores, um instrumento que ajudará na qualidade do ensino e no desenvolvimento da escola na política de gestão democrática, relatam que a lei 1.503 de 2010 continua na gaveta mesmo ela possuindo o caráter democrático e participativo. 
Outra equipe que assumiu, achava que deveriam conduzir da forma deles, acham que a forma como foi conduzida na primeira eleição não era da forma como eles estavam já planejando pra ser e conduziram, quer dizer que houve uma quebra ai do trabalho, não houve uma avaliação do que foi feito[...] (Entrevistado 07)

No Amapá esse comitê não foi criado até hoje, a lei foi criada em 2010 e diga-se de passagem essa lei foi criada por um executivo que não queria a lei, ele assinou no último dia de possibilidade antes de uma eleição, quer dizer que já é uma lei criada por um mandato e jogou para outro mandado, como se diz: -toma esse negócio aí que é ruim [...] o próximo que chegou não gostou também 2011 entrou, 2012, 2013 e só 2014 que se conseguiu fazer essa eleição, 2015 acabaria já esse mandato, bem próximo do final. (entrevistado 06)

A não criação deste Comitê de Avaliação das Políticas Públicas Estadual de gestão democrática se mostra como um ponto negativo a lei 1.503 de 2010. Desse modo, os membros da Coordenação Permanente de Organização e Acompanhamento dos Processos Eleitorais fizeram críticas em seus discursos sobre este ponto. Não se afirma, no entanto, que outras fragilidades não sejam importantes, mas esta se mostra mais latente e enfraquece a implementação da lei 1.503 de 2010, tornando-se um óbice inclusive aos passos que já deveriam está consolidados como é o caso dos diretores eleitos que, por previsão legal, podem ter suas eleições impugnadas, configurando-se no atual panorama de Gestão Democrática do Estado do Amapá.

\section{Considerações Finais}

A política de escolha de gestores escolares, a qual se denominou de Gestão Democrática no presente artigo, carrega consigo um conjunto de significados intrínsecos as políticas públicas sociais como é o caso da educação, pois a eleição de um diretor escolar por si só não garante o viés democrático deste processo, desse modo, algumas recomendações são pertinentes.

Primeiramente, é necessário esclarecer que houveram conquistas no processo de Gestão democrática no Estado do Amapá e sem dúvidas a promulgação da Lei 1.503 de 2010 que prevê a eleição para gestores escolares é a maior delas, pois, até então, a indicação era feita pelo poder discricionário concedido ao chefe do poder executivo estadual salvaguardado pela Constituição Estadual de 1991.

Por conseguinte, é preciso que a Secretaria de Educação do Estado da Educação do Amapá (SEED-AP) dê todo o suporte necessário às escolas e demais instituições envolvidas nos processos que antecedem e sucedem as escolhas dos dirigentes escolares de suas unidades de ensino. É necessário a implementação da Lei 1.503 de 2010 de forma efetiva e eficiente, logo até o ano 2019 (data de finalização do presente trabalho) das 396 escolas da rede estadual de ensino, somente 10 possuíam a gestão democrática, via eleição de gestores.

A SEED-AP precisa intensificar formações nas escolas sobre a gestão democrática visando a maior participação da comunidade escolar, logo a falta de informação ainda é incipiente sobre a temática, fato este que se corrobora na quantidade de pleitos existentes até o momento. Desse modo, em 2017 um diretor não conseguiu sequer a participação mínima da comunidade escolar para que ocorresse a eleição em sua unidade de ensino. 
A falta de formações e informações não conseguiu reunir com os 10 conselhos escolares das escolas de Gestão Democrática, desse modo, há poucas assembleias gerais realizadas. Assim, no primeiro pleito em $2014 \mathrm{dez}$ escolas desistiram do processo eleitoral.

A Coordenação Permanente de Organização e Acompanhamento dos Processos Eleitorais (CEPE) precisa de uma equipe maior e direcionada apenas para os processos atinentes a escolhas de gestores, uma vez que seus membros possuem outras atividades dentro da SEED-AP. Outra fragilidade a ser corrigida é a rotatividade destes uma vez que no ano de 2017 os quatro membros que foram designados pelo Sindicato dos Servidores Públicos em Educação no Amapá (SINSEPEAP) foram substituídos por representantes da SEED-AP.

É necessário criar e implantar o Comitê de Avaliação das Políticas Públicas Estadual que deve realizar o assessoramento, acompanhamento, monitoração e avaliação para implementação do projeto político da gestão democrática para que ocorra nas unidades escolares o processo decisório tanto dos conselhos como da escolha de diretores. Esse comitê ajudará na qualidade do ensino e no desenvolvimento da escola na política de gestão democrática.

As unidades escolares de Gestão Democrática também precisam do envolvimento do Conselho Escolar, funcionários, alunos, SINSEPEAP, SEED-AP, ou seja, o apoio na construção compartilhada através da criação de uma comissão de caráter representativo para deliberar sobre as decisões de seus educandários, conforme prever a lei, isso se torna um ponto de conquista do processo de gestão democrática. Sem esta comissão todo processo fica fragilizado.

Resultados mais consolidados perecem de mais pesquisas neste campo do conhecimento. As ideias, objetivos, resultados e perspectivas do referido processo de Gestão Democrática constituem-se em um horizonte em construção que requerem cuidados em sua implementação e mais estudos acadêmicos direcionados em nível de graduação e pós-graduação.

\section{Referências bibliográficas}

AMAPÁ. Constituição do Estado do Amapá. Diário Oficial do Estado do Amapá. Amapá, 20 dez. 1991.

Lei n. 1.503, de 09 de julho de 2010. Dispõe sobre a regulamentação da gestão democrática escolar nas Unidades Escolares do Sistema Estadual de Ensino, prevista nos arts. 6ํㅜ e 7음 da Lei Estadual no 0949/2005, de 26 de dezembro de 2005, bem como em observância ao disposto no inciso VI do art. 206 da Constituição Federal, inciso II, do $§ 2^{\circ}$, do art. 285 da Constituição do Estado e ao inciso VIII do art. 3o da Lei no 9.394/1996 e dá outras providências. Diário Oficial do Estado. Amapá, 09 jul. 2010.

AVRITZER, Leonardo. A qualidade da democracia e a questão da efetividade da participação: mapeando o debate. In: PIRES, R. R. (Org.). Efetividade das instituições participativas no Brasil: estratégias de avaliação. Brasília, DF, 2011.

BARDIN, Laurence. Análise de Conteúdo. Lisboa: Ed. 70, 1977.

BRASIL. Constituição da República Federativa do Brasil. Diário Oficial da União, Brasília, 5 out. 1988. 
GHIRARDI, José Garcez; CUNHA, Luciana Gross. O voto do silêncio: abstenção eleitoral, representações da cidadania e participação política na pós-modernidade. Disponível em: http://editorarevistas.mackenzie.br/index.php/rmd/article/viewFile/5801/4217. Acesso em: 13 fev. 2018.

LAKATOS, Eva Maria; MARCONI, Marina de Andrade. Fundamentos de Metodologia Científica. São Paulo: Atlas, 2003.

LÜCK, Heloísa. Concepções e processos demonstrativos de gestão educacional. Petrópolis, RJ. Vozes, 2006. Série: Caderno de gestão.

Mapeamento de práticas de seleção e capacitação de diretores escolares.

Relatório Final. Fundação Victor Civita - CEDHAP - Centro de Desenvolvimento Humano Aplicado. 2011. Disponível em: <file:///C:/Users/ADM/AppData/Local/Packages/Microsoft.MicrosoftEdge_8wekyb3d8b bwe/TempState/Downloads/MAPEAMENTO\%20DE\%20PRÁTICAS\%20DE\%20SELEÇÃO \%20E\%20CAPACITAÇÃO\%20DE\%20DIRETORES\%20ESCOLARES.pdf>. Acesso em: 21 dez. 2017.

MARTINS, José do Prado. Gestão Educacional - Uma Abordagem Crítica do Processo Administrativo em Educação - 3a Ed. 2007

MINAYO, Maria Cecília de Souza (Organizadora). Pesquisa Social: Teoria, Método Criatividade. 28 ed. Petrópolis, RJ: Vozes, 2009.

Pesquisa Social: Teoria, Método Criatividade. Petrópolis, RJ: Vozes, 2016 (Série Manuais Acadêmicos).

PARO, Vitor Henrique. Por dentro da escola pública. 4. Ed. São Paulo: Cortez, 2016.

ROUSSEAU Jean-Jacques. Do contrato social. Tradução: Rolando Roque da Silva. Edição eletrônica: Ed Ridendo Castigat Mores, 2002. Disponível em: <http://www.dominiopublico.gov.br/download/texto/cv00014a.pdf>. Acesso em: 10 jan. 2018.

SANTOS, Boaventura de Sousa e AVRITZER, Leonardo. Para ampliar o cânone democrático. In: SANTOS, Boaventura de Sousa (org.). Democratizar a democracia: os caminhos da democracia participativa. Rio de Janeiro: Civilização Brasileira, 3a ed. 2005. 